Journal of Social Sciences (COES\&RJ-JSS)

ISSN (E): 2305-9249 ISSN (P): 2305-9494

Publisher: Centre of Excellence for Scientific \& Research Journalism, COES\&RJ LLC

Online Publication Date: 1st July 2016

Online Issue: Volume 5, Number 3, July 2016

http://centreofexcellence.net/J/JSS/JSS\%20Mainpage.htm

\title{
Justifications of the implementation of foreign judgments in Jordan
}

\author{
Nawal Hussien Jamil AL-Syaidh \\ Head of Human Resource, Youth \& Sport National Fund Support, Amman, Jordan,
}

\begin{abstract}
:
Authorized law enforcement of foreign judgments Jordanian implementation of judgments of foreign judicial views in the Hashemite Kingdom of Jordan, in accordance with the rules and special provisions and conditions are different. The implementation of this action is the most important laws that addressed the legislature in which many of the Jordanian relations and international transactions that arise between individuals or institutions of different kinds. Came the attention of the international community to the subject of foreign judgments and apply for legal reasons, and various procedural, including that of respect for acquired rights of the parties to legal relations, or related to the maintenance of international transactions that result in the rights and obligations of different or reciprocity. The importance of this research to the statement of justification for the application of foreign judgments in Jordan and other countries through the study of many related topics such as the force and respect for acquired rights and justifications for international transactions and others. The current research reviews the general provisions relating to foreign judgments in accordance with Jordanian law and some other legislation in the second part, and then studied the reasons and justifications for the implementation of foreign judgments.
\end{abstract}

\section{Keywords:}

Foreign judgments, Jordan.

\section{Citation:}

Al-Syaidh, Nawal Hussien Jamil (2016); Justifications of the implementation of foreign judgments in Jordan; Journal of Social Sciences (COES\&RJ-JSS), Vol.5, No.3, pp: 425-443.

This work is licensed under a Creative Commons Attribution 4.0 International License. 


\section{Justifications of the implementation of foreign judgments in Jordan}

\section{مبررات تطبيق الاحكام الاجنبية في الاردن}

نوال حسين جميل السيايدة، رئيس قسم الموارد البشرية، الصندوق الوطني لاعم الحركة الثبابية والرياضية، عمان/الأردن، المنان،

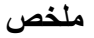

اجاز قانون تنفيذ الاحكام الاجنبية الاردني تنفيذ الاحكام الصادرة عن جهات قضائية اجنبية في المملكة الاردنية

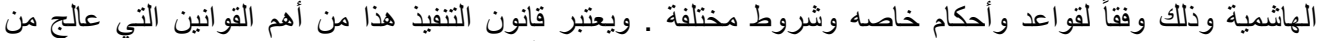

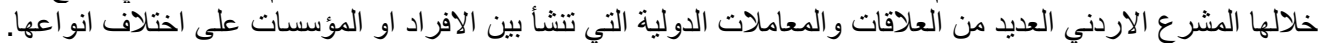

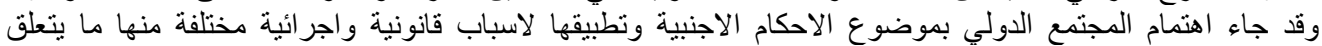

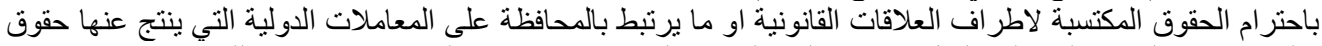

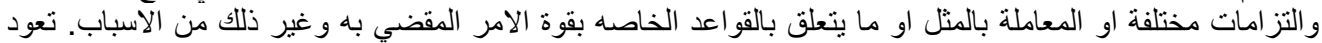

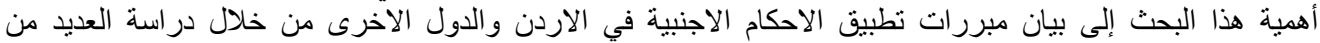

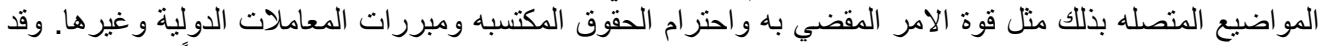

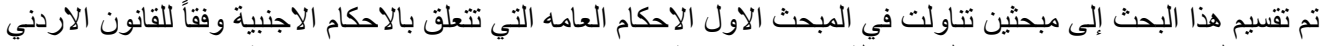

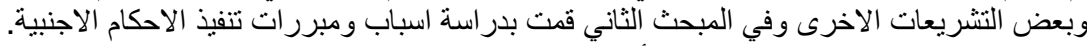
الكلمات الدالة: تنفيذ الاحكام الاجنبية ، الأردن.

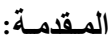

لقد اشتار المشرع الاردني في المادة الثالثة من قانون تنفيذ الاحكام الاجنبية الاردني الى جواز تتفيذ الحكم الاجنبي في المملكة الاردنية الهاشمية باقامة دعوى لتتفيذه امام محكمة بدائية ـ وأن المحكمة التي بطلب إليها تصديق الحكم الأجنبي أو إكسائه صيغة التتفيذ لا تملك مناقشة موضوعه أو التعديل فيه وتتحصر مهمتها بمراقبة توفر شروط نتفيذه حسب أحكام

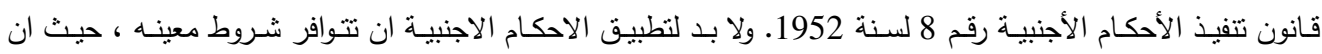
الأحكام والأوامر الصـادرة فى بلد أجنبى يجوز الأمر بتتفيذها بنفس الثروط المقررة فى قانون ذلك البلد لتتفيذ الأحكام والأوامر المطبقة في بلد اخر . الامر

$$
\begin{aligned}
& \text { تتص الفقرة الأولى من المادة السابعة من قانون تتفيذ الأحكام الأجنبية رقم (8 ) لسنة } 1952 \text { على ما يلي: } \\
& \text { 1. يجوز للمحكمة أن ترفض الطلب المرفوع إليها لتنفيذ حكم أجنبي في الأحوال الآتية: } \\
& \text { أ -إذا لم تكن المحكمة التي أصدرت الحكم المذكور ذات وظيفة. }
\end{aligned}
$$

ب -إذا كان المحكوم عليه لم يتعاط أعماله داخل قضاء تشمله صـلاحية المحكمة التي أصدرت الحكم أو لم يكن مقيمًا داخل

$$
\text { قضائها ولم يحضر باختيار أمام المحكمة ولم يعترف بصايلاحيتها." }
$$

" فقاضي التتفيذ في الأردن ينفذ الحكم الأجنبي إذا توافرت جميع شروط المادة السابعة من قانون تتفيذ الأحكام الأجنبية، ومن ضمن هذه الثروط اختصاص المحكمة الأجنبية التي أصدرت الحكم المراد تتفيذه في المملكة .فقاضي التنفيذ الأردني عندما يتحقق من اختصاص المحكمة الأجنبية التي أصدرت الحكم يستند إلى أي قانون، قانون المحكمة الأجنبية التي أصدرت الحكم أم قانونه؟ لم يرد في قانون تنفيذ الأحكام الأجنبية الأردني نص صربح بهذا الثأن لذلك نستتتج من مفهوم المخالفة لنص المادة السابعة من قانون تتفيذ الأحكام الأجنبية أن المحكمة تتفذ الحكم الأجنبي إذا كانت المحكمة التي أصدرت 
الحكم ذات وظيفة واذا كان المحكوم عليه يتعاطى أعماله داخل قضاء تشمله صسلاحية المحكمة التي أصدرت الحكم أو كان

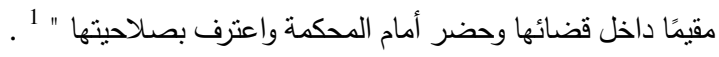

وقد اشـار الدكتور الحجايا الى الاتفاقيات التي وقعت بين المملكة الأردنية الهاشمية مع دول مختلفة المتعلقة بالتعاون القانوني والقضائي، ومن هذه الاتفاقيات : اتفاقية الرياض العربية للتعاون القضائي، اتفاقية تتفيذ الأحكام بين دول الجامعة العربية ، اتفاقية التعاون القانوني والقضائي بين دول مجلس التعاون العربي، اتفاقية التعاون القضائي بين الأردن وجمهورية مصر العربية، الاتفاقية القضائية بين الأردن والجمهورية السورية، اتفاقية التعاون القضائي بين الأردن والجمهورية السورية، اتفاقية التعاون القضائي بين الأردن والجمهورية اليمنية، اتفاقية التعاون القانوني والقضائي بين دولة الإمارات والأردن والاتفاقية القضائية اللبنانية الأردنية ، إعلان الاتفاق القضائي بين الأردن ولبنان، والاتفاقية القضائية بين تونس والأردن. وباستقراء التتريعات المتعلقة بتفيذ الاحكام الاجنبية في الاردن وكذلك الاتفاقيات المختلفة التي تشير الى مبدأ الالزام في تطبيق الاحكام الاجنيية التي تصدر عن هيئات قضائية مختصـة في البلدان التي تكون طرف في معاهدة او اتفاقية معينه • وتعود اسباب الالتزام بتنفيذ الحكم الاجنبي الى العديد من الاسباب القانونية والاجرائية والتي تتعلق بطبيعة تلك الاحكام

ومدى التزام الدول بالمحافظة على حقوق الغير وغيرها من الاسباب .

لقد قمت بتقيم هذا البحث إلى مبحثين تتاولت في المبحث الاول الاحكام العامه التي تتعلق بتتفيذ الاحكام الاجنبية وفقاً للقانون الاردني وبعض التشريعات الاخرى وفي المبحث الثاني الاسباب التي دعت الدول الى تطبيق الاحكام الاجنبية

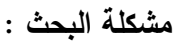

ترجع مشكلة البحث الى بيان وتحديد الاسباب التي ينت من خلالها تبرير تتفيذ الاحكام الاجنبية على ارض دولة اخرى

غير مصدرة الحكم الذي اكتسب الدرجة القطعية ، ولذا تكمن مشكلة البحث فيما يلي :

1

2.

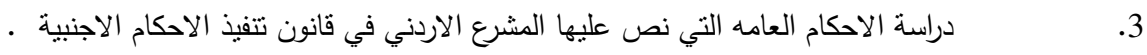

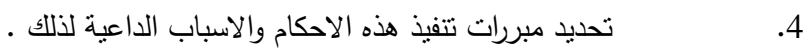

5. دراسـة بعض النتـربعات الاردنيـة والدوليـة والاتفاقيات المختلفة المتعلقة بهذا المجال ومدى تطبيقها وتتفيذها

للاحكام الاجنبية على اراضيها .

أهمية البحث :

تكمن اهمية هذا البحث في بيان كافة الامور المتعلقة بتنفيذ الاحكام الاجنبية في الاردن والدول الاخرى واسباب الالنزام

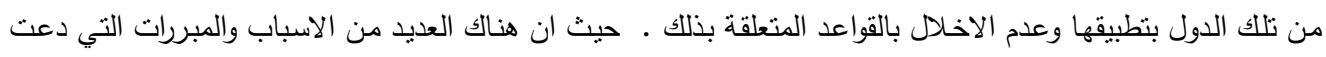

1 ـ انظر نور الحجايا ، رقابة الاختصاص القضائي عند تتفيذ الاحكام الاجنبية في الاردن ، بحث منشور في جامعة

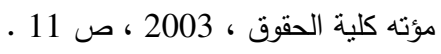


Justifications of the implementation of foreign judgments in Jordan

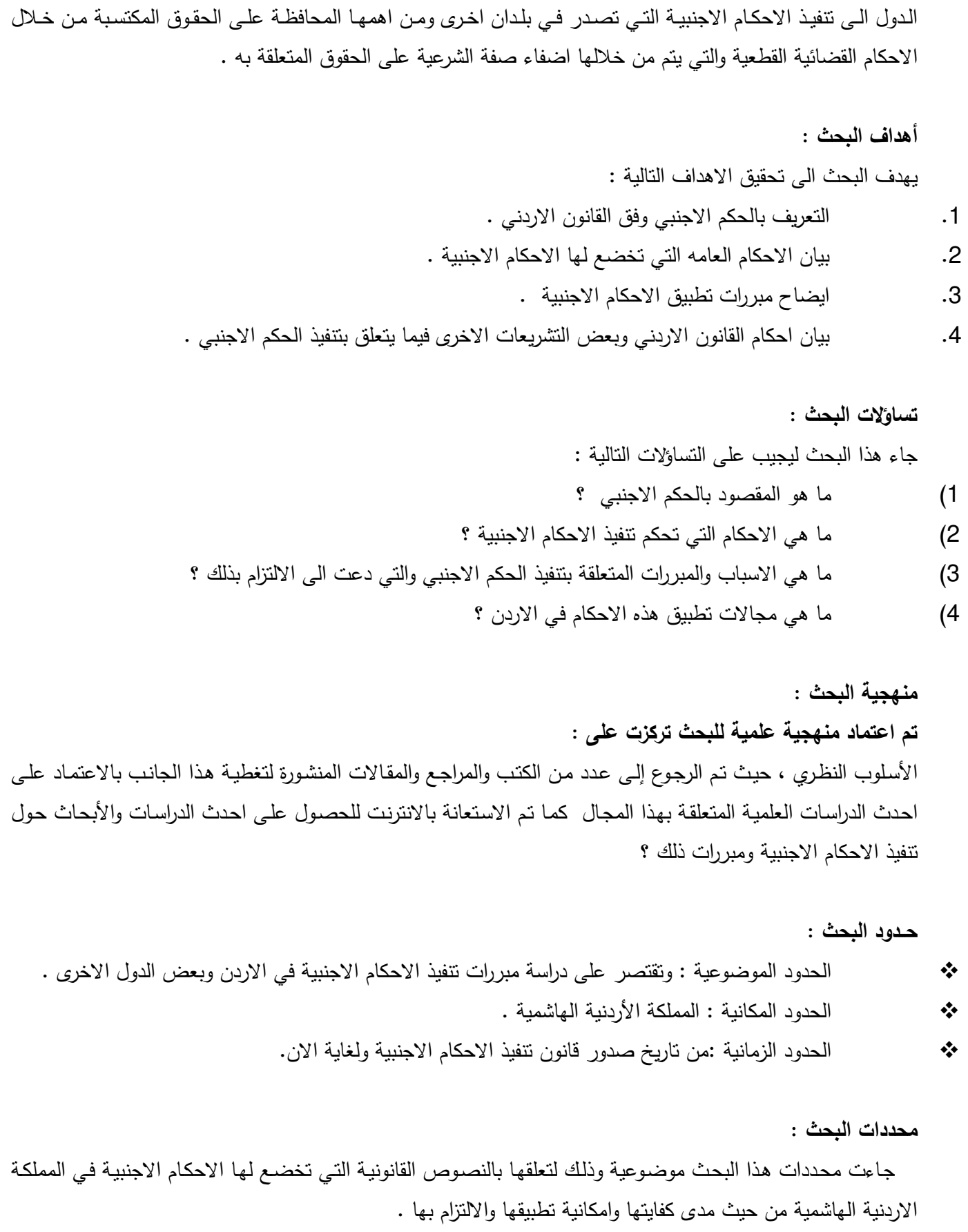


Journal of Social Sciences (COES\&RJ-JSS), 5(3), pp. 425-443

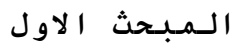

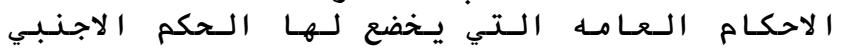

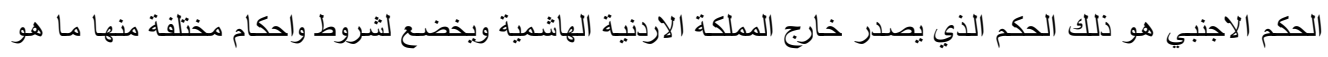

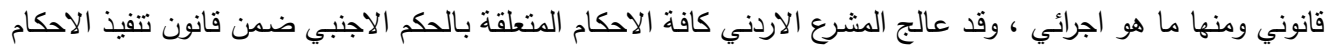

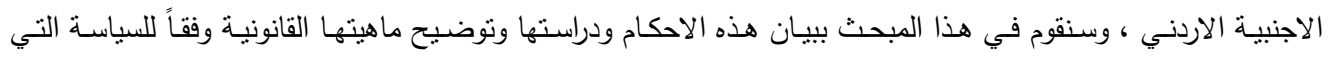

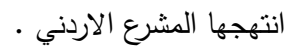

\section{الـمطلب الاول \\ الـمـاهيـة الـقــانـونـيـة لـلحكم الاجنـبـي}

عالج المشرع الاردني موضوع تتفيذ الاحكام الاجنيية في القانون رقم ( 8 ) لسنة 1952 وأوضح بان الحكم الاجنبي هو

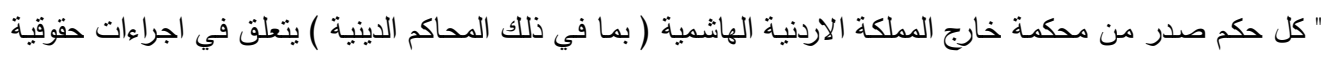

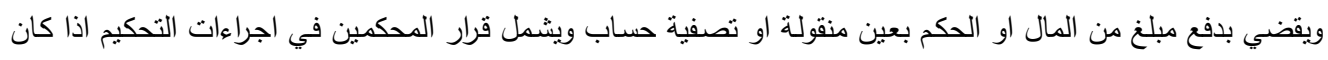

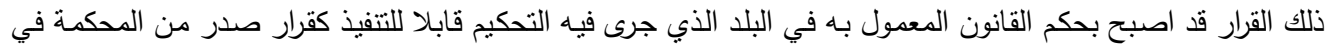

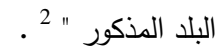

ويقول الدكتور صالح المنزلاوي ان " الحكم الأجنبي صادرًا عن هيئة قضائية فإذا كان الدقصود بالحكم في مجال تتفيذ

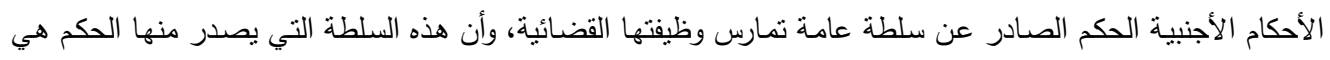

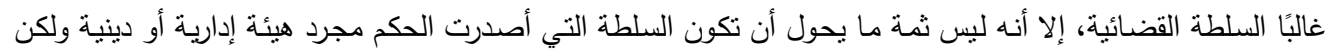

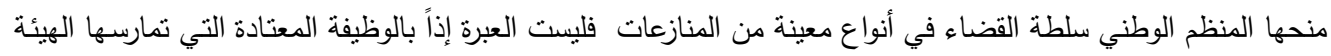

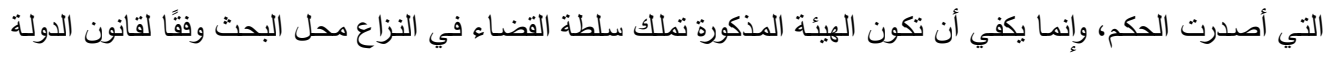

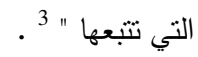

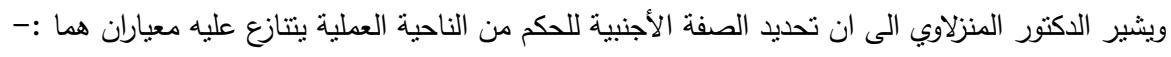

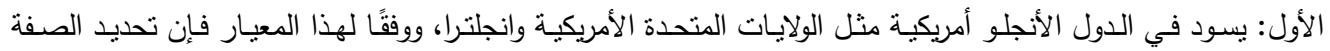

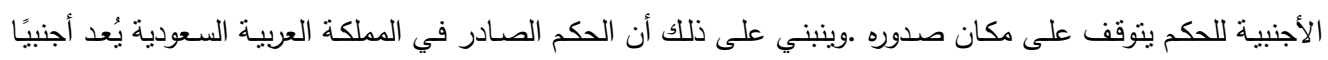
بالنسبة لفرنسا، وأن الحكم الصادر في ولاية أمريكية يعتبر أجنيبًا بالنسبة لسائر الولايات الألمريكية الأليكية.

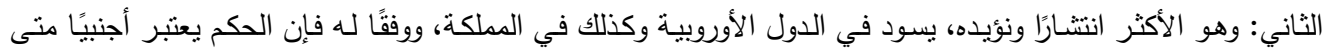

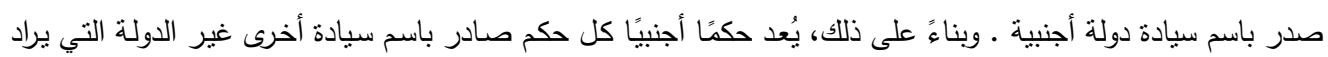
تتفيذه فيها أو مد آثاره إليها، ولا يهم بعد ذلك مكان صدور الحكم ولا جنسية القضاة الذين يفصلون في الخصومة بـأ.

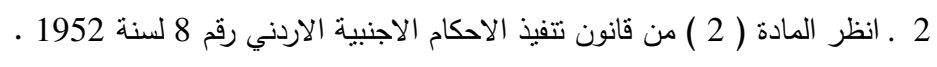

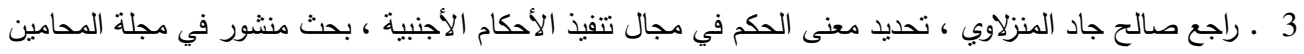

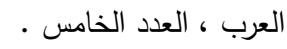

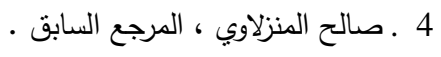




\title{
Justifications of the implementation of foreign judgments in Jordan
}

\author{
الـمطلب الـثـانـي \\ احكـام تـنفيـذ الـحكم الاجنبـي في الاردن
}

أشـارت المادة الثالثة من قانون تتفيذ الاحكام الاجنبية الاردني الى جواز تنفيذ الحكم الاجنبي في المملكة الاردنية الهاشمية باقامة دعوى للتفيذه امام محكمة بدائية ـ وأن المحكمة التي يطلب إليها تصديق الحكم الأجنبي أو إكسائه صيغة الإنة

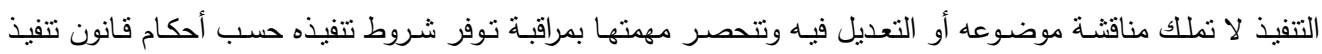
الأحكام الأجنبية رقم 8 لسنة 1952. ان مهمة المحكمه طبقاً لقانون تتفيذ الأحكام الأجنبيه ولغايات اكساء الحكم الأجنبي فروطي

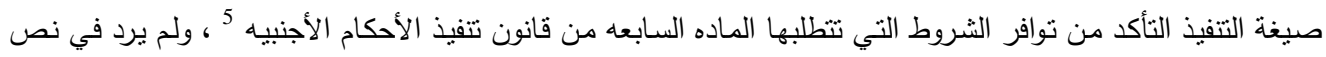

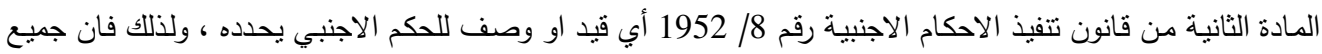

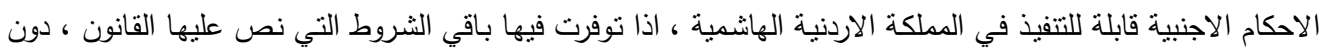
ان يتوقف ذلك على وجود اتفاقية تتفيذ الاحكام بين الاردن والبلد التي صدر فيه الحكم المطلوب تتفيذه.

وقد قررت محكمة التمييز الاردنية انه " اذا حضر المستدعي والمستدعى ضده لادى لجنة النوفيق والمصالحة في دولة

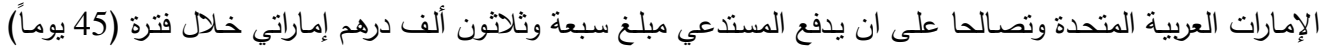

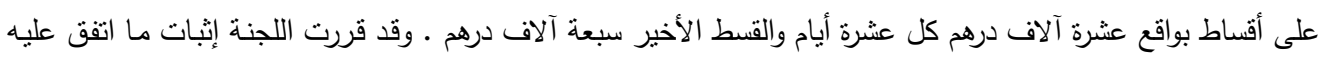

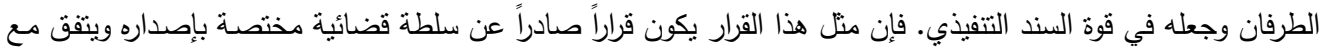

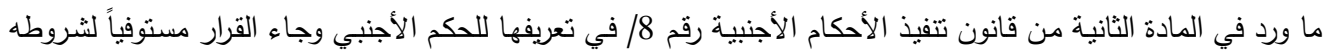

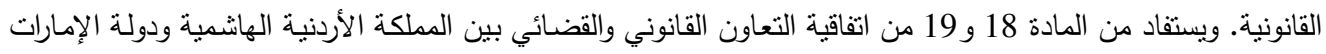

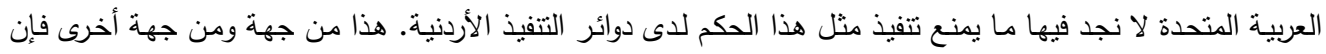

5 ـ لمزيد من التفصيل راجع قرار محكمة التمييز الاردنيـة بصفتها الحقوقيـة رقم 2003/12/4 (هيئة خماسية) تاريخ 2003/12/4 ، منشورات مركز عدالة ـ وقد نصت المادة السابعة من قانون تنفيذ الاحكام الاجنبية على انه يجوز للمحكمة ان ترفض الطلب المرفوع اليها لتنفيذ حكم اجنبي في الاحوال التالية :

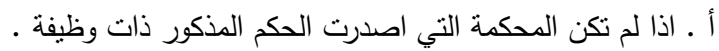
ب. اذا كان المحكوم عليه لم يتعاط اعماله داخل قضاء تشمله صلاحية المحكمة التي اصدرت التهات الحكم او لم يكن مقيما داخل قضائها ولم يحضر باختياره امام المحكمة ولم يعترف بصلاط اعلاحيتها.

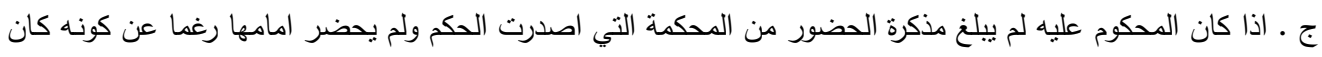

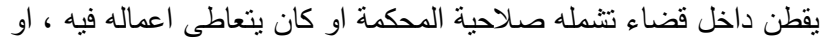
د. ـ اذا كان الحكم قد حصل عليه بطريق الاحتيال .

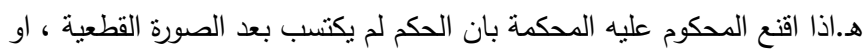
و. اذا كان الحكم بسبب دعوى لا تسمعها محاكم الملكة الاردنية الهاشمية اما لمخالفتها للنظام العام او الآداب العامة.

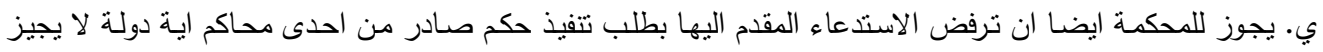

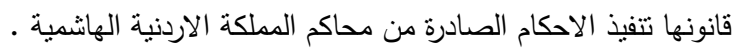




\section{Journal of Social Sciences (COES\&RJ-JSS), 5(3), pp. 425-443}

الاتفاقية لم تشترط التصديقات على الأحكام ما اثشترطته المادة 26 من قانون البينات لاثبات صحة تتظيم أي عقد او وكالة

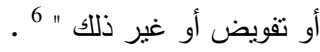

وفي قرار لمحكمة التمييز الاردنية انه " يستفاد من أحكام المادة الثانية من قانون تتفيذ الأحكام الأجنبية رقم 8 لسنة

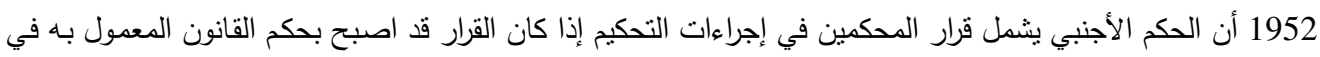

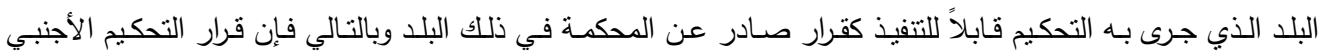
المطلوب تتفيذه والمصدق عليه من قبل الجهات المختصة في ذلك البلد يكون قابلاً للتنفيذ في الأردن إذا كان مستوفياً

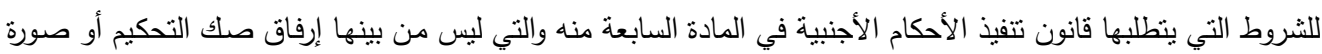

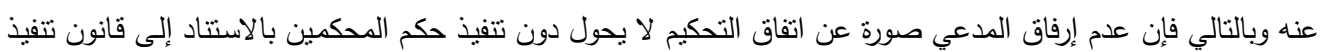

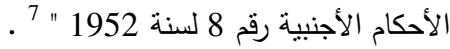

وتقام الدعوى بطلب تتفيذ حكم اجنبي باستدعاء يقدم الى المحكمة البدائية التي يقيم المحكوم عليه ضمن صـاحياتها

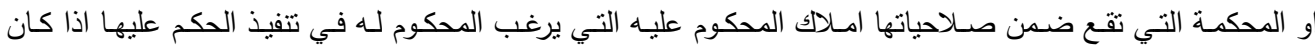
المحكوم عليه لا يقيم في المملكة الاردنية الهاثمية فاذا لم يكن للمدعى عليه موطن ولا سكن في الاردن ولم يتيسر تعيين

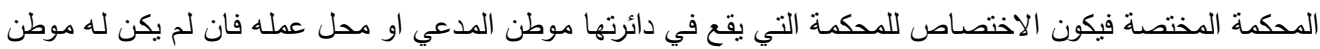
ولا محل عمل في الاردن كان الاختصاص لمحكمة بداية عمان وذلك عملا بالمادة 4 من قانون تتفيذ الاحكام الاجنيبة والمادة 47 من قانون اصول المحاكمات المدنية .

وقد بين المشرع الاردني بانه تسري احكام قانون اصول المحاكمات الحقوقية على الدعاوى التي نقام وفق قانون تتفيذ الاحكام الاجنبية ، وقد قضت محكمة التمييز الاردنية " ان الاصل ان يقدم الطلب من المحكوم له بالحكم الاجنبي، سواء التهاء

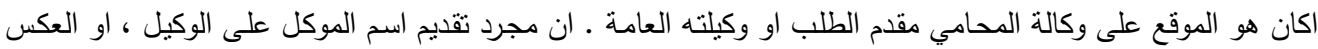

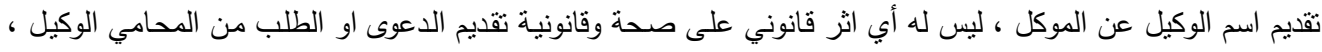

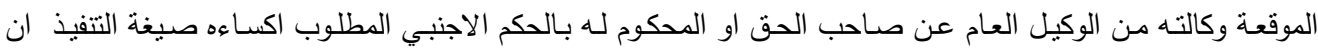

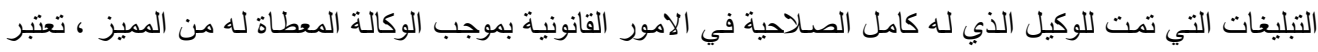
تبليغات قانونية ، ومع ذلك تم تبليغ المميز نفسه بالنشر في صحيفتين يوميتين ، وحيث ان المميز لم يقدم ما يثبت عدم لهات

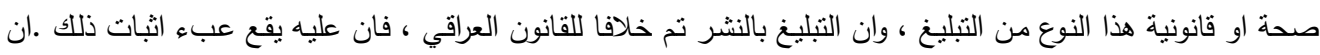

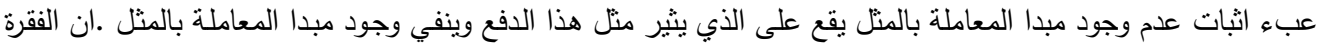

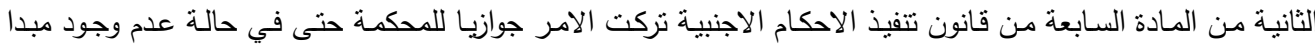
المعاملة بالمتل ، ولم يوجبه على المحكمة وجوبا بيعتبر نص المادة 72 من الاصول المدنية نص عام ، ويمثل اجراءات

6 ـ قرار محكمة التمييز الاردنيـة بصفتها الحقوقيـة رقم 2006/3916 (هيئة خماسية) تاريخ 2007/8/16 منشورات مركز عدالة . 7 ـ قرار محكمة التمييز الاردنية بصفتها الحقوقية رقم 2004/2923 (هيئة خماسية) تاريخ 2004/11/30منشورات مركز 


\section{Justifications of the implementation of foreign judgments in Jordan}

جميع انواع الدعاوى ، بما فيها دعوى طلب اكساء الحكم الاجنبي صيغة التنفيذ ، ولم يستنن من حكمها أي نوع أي نوع

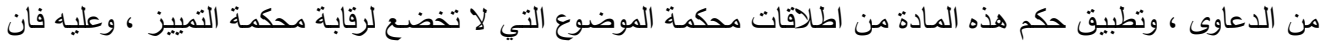

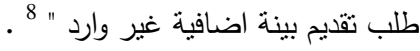

كما أوضـح المشرع الاردني في المادة التاسعة من قانون تتفيذ الاحكام الاجنبية بان الاحكام الصـادرة بموجب هذا القانون تنفذ بالطريقة التي تتفذ فيها الاحكام الصادرة من محاكم المملكة الاردنية الهانمية.

يستفاد من المادة (17) من الاتفاقية القضـائية المعقودة بين حكومـة المملكة الاردنية الهاثـمية وحكومة الجمهوريـة اللبنانية انها اوجبت ان يقدم طلب تتفيذ الحكم الاجنبي الى السلطة القضائية طبقا لاحكام قانون الدولة الدقدم اليها الطلب .

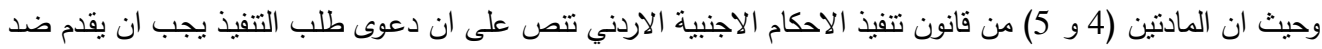

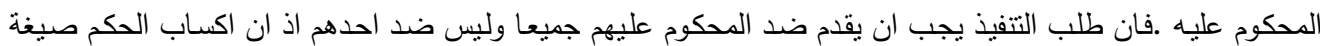
التنفيذ يترتب عليه وجوب تتفيذ الحكم ضد الحكوم عليهم جميعا دون ان يكونوا طرفا في دعوى طلب التنفيذ الامر

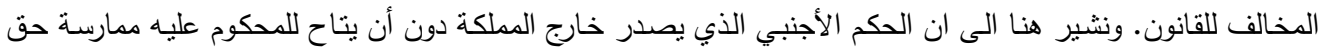
الدفاع هو حكم لا يقبل التففذ في المملكة ، وذلك لقسية هذا الدق بالنسبة للمحكوم عليهم .

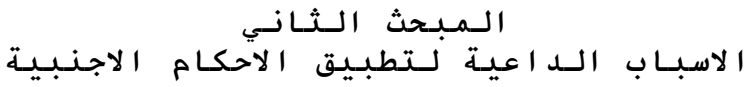

ان هناك العديد من الاسباب التي دعت المشرع الاردني الى الالتزام بتطبيق اي حكم اجنبي يصدر في اي دولة

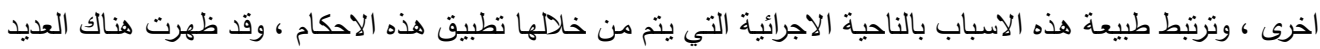
من التطبيقات القضائية التي اوضحت اركان ومظاهر تتفيذ الحكم الاجنبي ، وسنقوم في هذا المبحث بدراسـة اسباب ومبررات تطبيق الحكم الاجنبي في الاردن ومظاهر التطبيقات القضائية المنعلقة بذللك. ونشير هنا الى انه قد يتم استبعاد التهاد

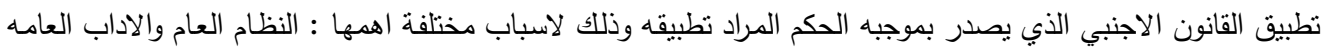
وذللك عندما يتعارض القانون مع المبادىء والدعائم الاساسية للاولة ، وعندما يكون هناك غش او تحايل نحو القانيان القانون المراد تطبيقه ، وهناك حالات اخرى قد تتعلق بالمصلحة الوطنية للاولة.

$$
\text { مـبـرر ات تـنفـيـــلـألاحكـام الاول الاجنـبـيـة }
$$

حقيقة ، ثار جدل كبير حول أساس تطبيق الحكم الاجنبي والمبررات التي تدعو الى ذلك ، فرد البعض هذه المبررات

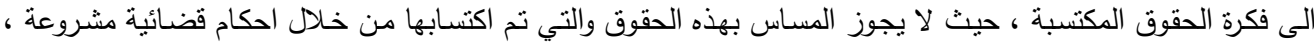
ورد البعض الاخر هذه المبررات الى ما يعرف بحجية الاحكام القضائية وانها تكتسب قوة الثيء المقضي بهاه، بينما اشتار 8 8 قرار محكمة التمييز الاردنية بصفتها الحقوقية رقم 2002/403 (هيئة خماسية) تاريخ 2002/2/20 منشورات مركز 
Journal of Social Sciences (COES\&RJ-JSS), 5(3), pp. 425-443

البعض الى ما يعرف بالاسباب الدولية المتعلقة بالتعاملات المدنية والتجارية وحتى الثخصية ، واحترام الاحكام القضائية والاعتراف بالاختصاص القضائي في الدول لمختلفة .

ان المادة (3) من قانوان تتفيذ الاحكام الاجنبية لسنة 1952، قد نصت : ( يجوز تتفيذ الحكم الاجنبي في المملكة

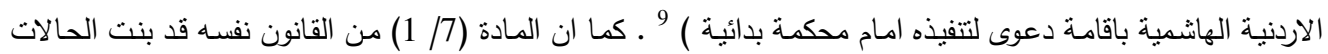
التي يجوز للمحكـة فيها ان ترفض الطلب المرفوع اليها لتنفيذ حكم اجنبي ، كما يجوز للمحكمة ان ترفض الاستـدعاء المقدم اليها بطلب تنفيذ حكم صـادر من احد محاكم أي دولة لا يجيز قانونها تتفيذ الاحكام الصادرة من محاكم المملكة

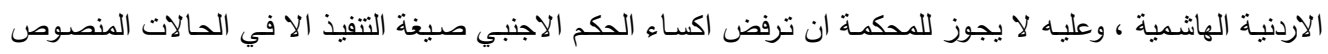

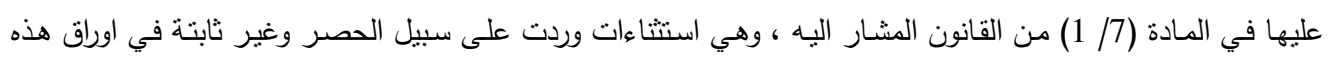
الدعوى وبيناتها، ولا تسنطيع المحكمة ان تخرج عن تلك الحالات المحددة .

وقد نصت المادة الأولى من اتفاقية تنفيذ الأحكام في دول الجامعة العربية على أن : (كل حكم نهائي مقرر لحقوق مدنية أو تجارية أو قضاء بتعويض من المحاكم الجنائية الجزائية أو متعلق بالأحوال الشخصية صادر من هيئة قضائية في إحدى دول الجامعة العربية يكون قابلاً للتنفيذ في سائر دول الجامعة وفقاً لأحكام هذه الاتفاقية) ونصت المادة الثالثة من ذات الاتفاقية على أنه: (مع مراعاة ما ورد في المادة الأولى من هذه الاتفاقية لا تملك السلطة المطلوب إليها تتفيذ حكم محكمين صادر في إحدى دول الجامعة العربية إعادة فحص موضوع الدعوى الصادر فيها حكم المحكمين المطلوب تتفيذه وإنما لها أن ترفض طلب تتفيذ حكم المحكمين المرفوع إليها في الأحوال الآتية: 1. إذا كان قانون الدولة المطلوب إليها تتفيذ الحكم لا يجيز حل موضوع النزاع عن طريق التحكيم.

2. إذا كان حكم المحكمين غير صادر تتفيذاً لشرط أو لعقد تحكيم صحيحين.

3. إذا كان المحكمن غير مختصين طبقاً لعقد أو شرط التحكيم أو طبقاً للقانون الذي صدر قرار المحكمين على مقتضاه.

4. إذا كان الخصوم لم يعلنوا بالحضور على الوجه الصحيح.

5. إذا كان في حكم المحكمين ما يخالف النظام العام أو الآداب العامة في الدولة المطلوب إلبها التتفيذ وهي صاحبة السلطة

في تقدير كونه كذللك وعدم تتفيذ ما يتعارض منه مع النظام أو الآداب العامة فيها. 6. إذا كان حكم المحكمين ليس نهائياً في الدولة التي صدر فيها.

ونصت المادة السادسة من ذات الاتفاقية على أن : (يكون للأحكام التي يتقرر تتفيذها في إحدى دول الجامعة نفس

القوة التنفيذية التي لها في محاكم الدولة طالبة التنفيذ).

لقد اولى المشرع الاردني تتفيذ الاحكام الاجنبية اهتماما بالغا وذلك لاسباب ومبررات مختلفة ، ويمكننا حصرها بما :لي

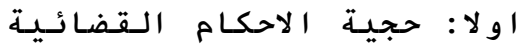
9 ـ قرار محكمة التمييز الاردنية بصفتها الحقوقية رقم 1997/1946 (هيئة خماسية) تاريخ 1997/12/15 المنشور على الصفحة 196 من عدد المجلة القضائية رقم 6 بتاريخ 1997/1/1 ـ 


\section{Justifications of the implementation of foreign judgments in Jordan}

اي عدم المساس بالقاعدة القانونية التي تقضي بقوة الثيء المقضي بـه ومضمون هذه القاعدة هو مـا نصت عليه المادة 40 من قانون البنات الاردني حيث نصت على ان " الاحكام التي حازت الدرجة القطعية تكون حجة بما فصلت فيه

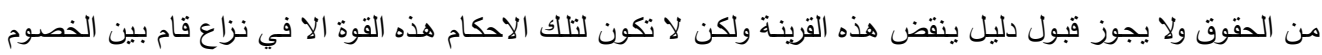

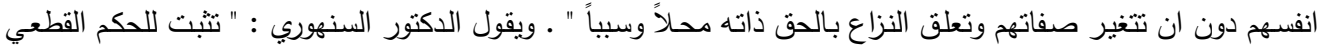

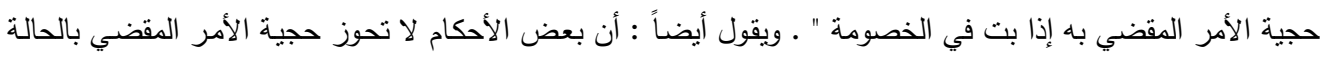

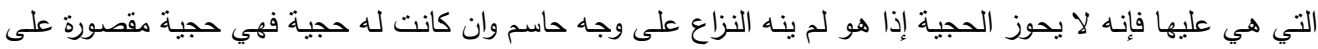

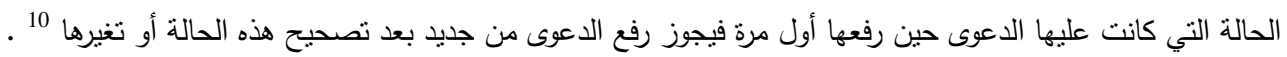

ويقول الدكتور محمد عرفه " وتبدو أهمية تنفيذ الأحكام القضائية بصفة عامة في أنه يُعد الإجراء العملي لبيان أهمية

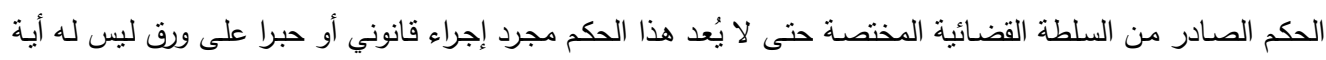

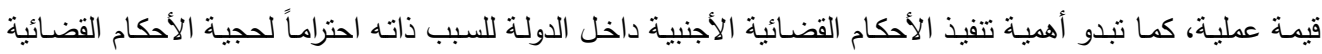
الصادرة من السلطات المختصة في الدول الأجنبية " 11 . وهناك العديد من الاحكام القضائية الصادرة عن محكمة التمييز الاردنية حول اكتساب الاحكام الدرجة القطعية في

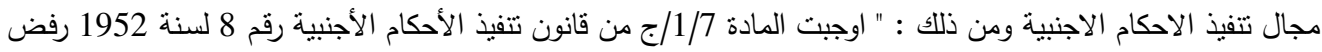

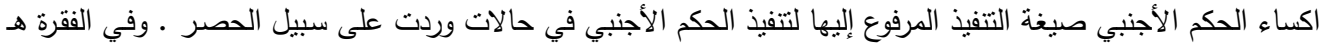

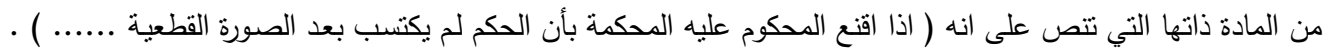

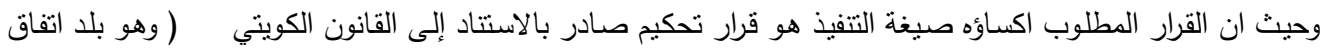

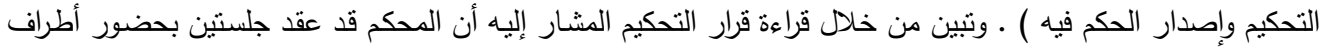

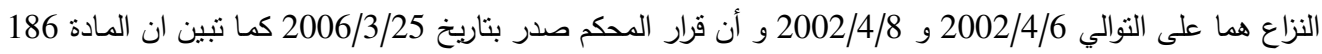

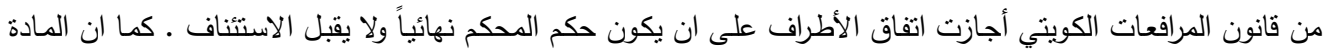

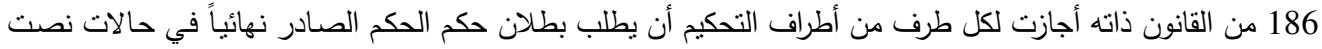

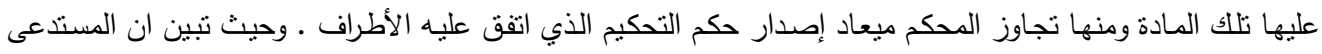

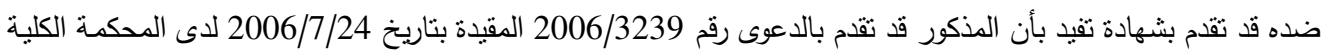
في الكويت بمواجهة المستدعي وآخر وانه تحدد موعد جلسة لنظرها في 2006/10/9 وتبين أن المستدعى ضده وفي

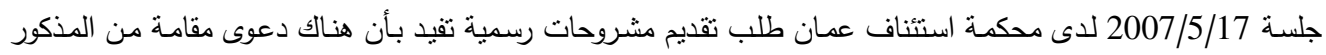
لابطال حكم التحكيم موضوع هذه الدعوى ـ وان محكمة استئناف عمان لم تستجب لهذا الطلب ـ وعليه فان إبراز هذه إنها المشروحات هو أمر ضروري للفصل في الطلب. وحيث أن المادتين 59 و 100 من قانون أصول المحاكمات المدنية

10 ـ انظر عبد الرزاق السنهوري ، الوسيط في شرح القانون المدني الجزء الثاني صفحة 659 وما بعدها .

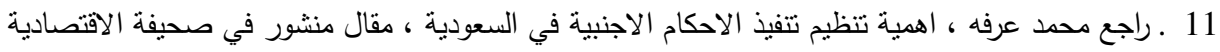

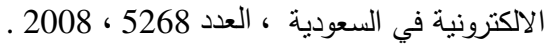




\section{Journal of Social Sciences (COES\&RJ-JSS), 5(3), pp. 425-443}

أجازتا لمحكمة الموضوع إبراز مستتدات ترى أنها لازمة للفصل في الدعوى فقد كان على محكمة استئناف عمان اجابة طلب المستدى ضده بهذا الخصوص ومن ثم ترتيب الاثر القانوني على هذا المستتد 12 . ل.

وقضت ايضاً " تكون الأحكام التي حازت الدرجة القطعية حجة بما فصلت فيه وفقاً لأحكام المادة 41 من قانون اليينات ـ ولمحاكم البداية الحق في اكساء الحكم الأجنبي صيغة التتفيذ ومن حقها تقدير فيما إذا كانت شروط الاكساء الاكساء

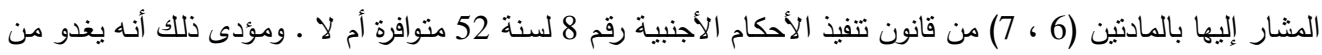

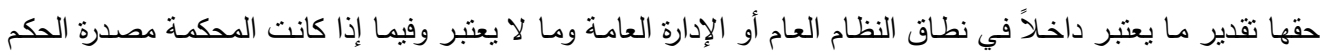

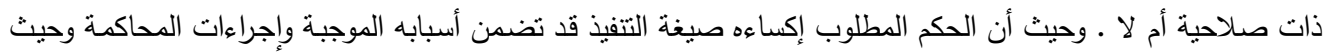

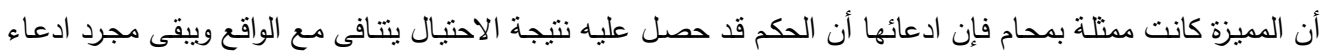

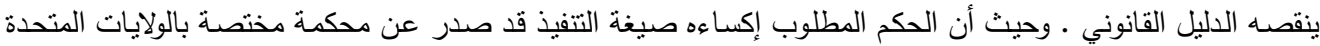
الأمريكية ومكتسب الدرجة القطعية ويتضمن الحكم على المستدعى ضدها المميزة بأتعاب محاماة ومصاريف حسب الفي القوانين النافذة في الولايات المتحدة الأمريكية وليس فيه ما يخالف القوانين الأردنية ـ لذلك يكون قرار محكمة الاستئناف يتفق وحكم القانون " 13

وفي حكم اخر " من المستقر عليه قانوناً وفقهاً وقضاءاً أن الحكم يحوز الدرجة القطعية أو قوة القضبة المقضية إذا

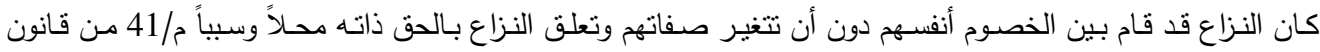

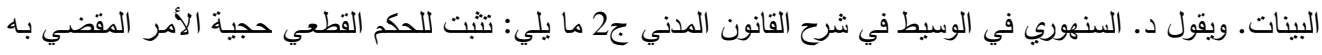

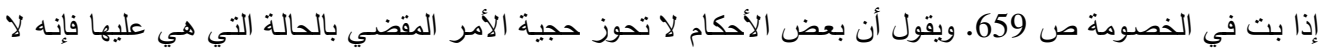
يحوز الحجية إذ هو لم ينه النزاع على وجه حاسم وإن كانت لله حجية فهي حجية مقصورة على الحالة الني كانت عليها

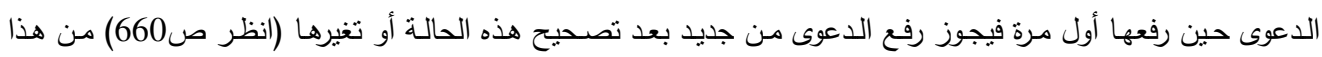

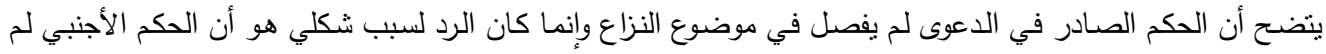

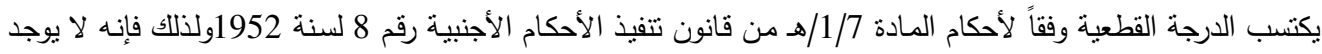

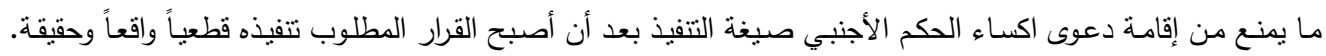
وحيث أن محكمة الاستئناف قد فصلت في الدعوى ومن قبلها محكمة البدايـة دون أن تتأكد من واقعة صيرورة الحكم

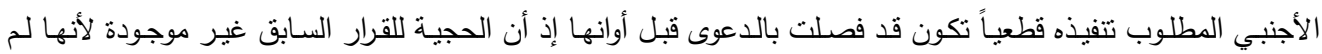

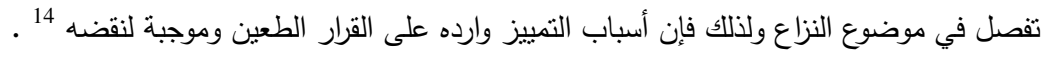

12 ـ قرار محكمة التمييز الاردنية (حقوق) رقم 2007/3197 (هيئة خماسية) تاريخ 2008/6/17 ، منشورات مركز عدالة

13 ـ قرار محكمة التمييز الاردنية بصفتها الحقوقية رقم 2007/1133 (هيئة خماسية) ناريخ 2007/10/16 منشورات

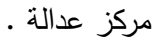
14 ـ قرار محكمة التمييز الاردنية بصفتها الحقوقيـة رقم 2006/1924 (هيئة خماسية) تاريخ 2006/12/10 منشورات

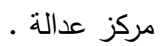




\section{Justifications of the implementation of foreign judgments in Jordan}

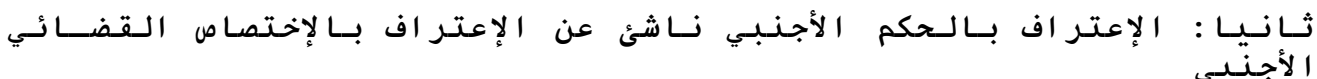

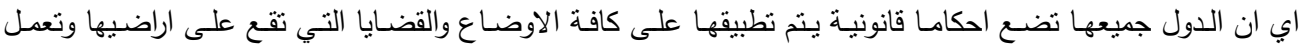

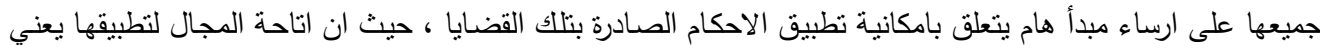

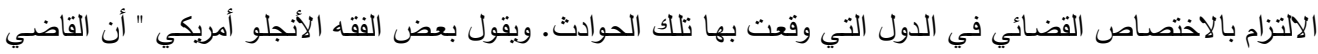

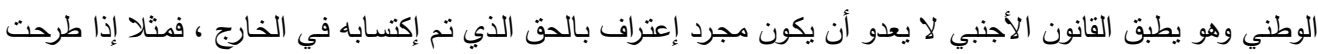

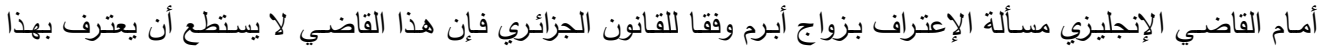

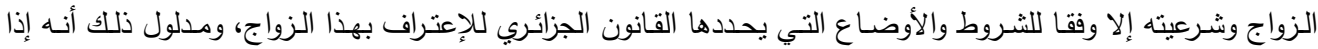
أثارت قاعدة الإسناد إلى تطبيق القانون الأجنبي فإنها تهذف إلى الإعتراف بالدق الذي نشأ وفق هذا القانون إذ أن القانون

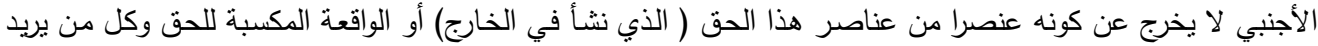

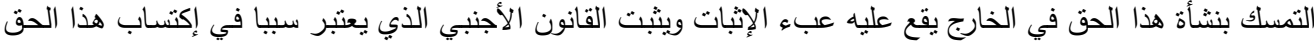
ومتى تمكن الخصم من إثبات حقه وفقا للقانون الأجنبي فما على القاضي إلا الإعتراف بهذا الحق الذي نشأ وتم إكتسابه

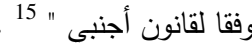

ونشير هنا الى قرار محكمة التمييز الاردنية حول تطبيق الحكم الاجنبي حتى في الحالة التي لا يكون هناك اتفاقية ثنائية ما بين الدولتين حيث قررت المحكمة بامه " يستفاد المادة (2/7) من قانون تتفيذ الأحكام الأجنبية نصت على التى أن لأن

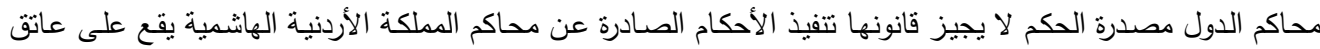

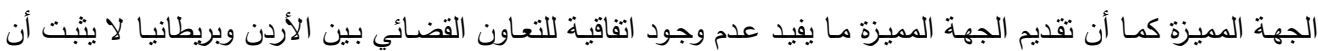
بريطانيا لا تتفذ الأحكام الصادرة عن محاكم المملكة الأردنية الهاشمية وكان على الجهة المميزة تقديم ما يثبت أن القانون

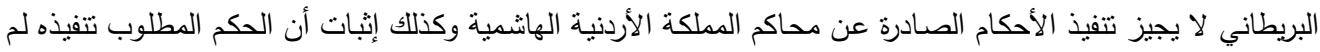

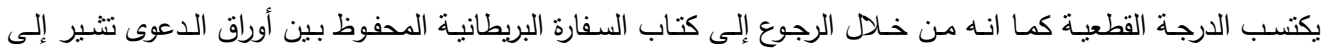

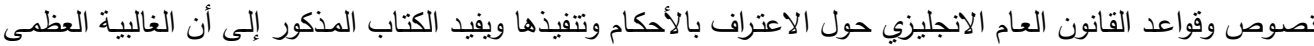

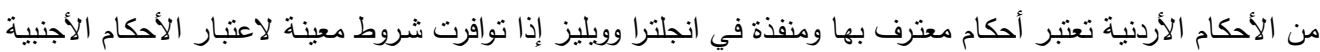

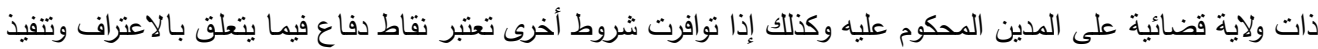

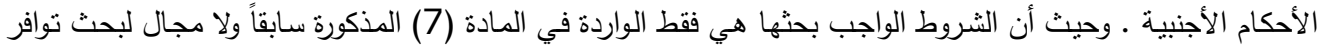

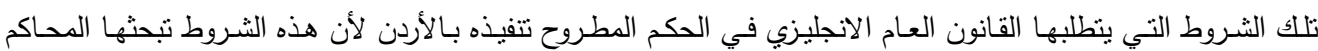
الانجليزية لغايات قبولها لتنفيذ الأحكام الأجنيية في محاكم المملكة المتحدة ـ وقد جرى الاجتهاد القضائي على أن المحكمة

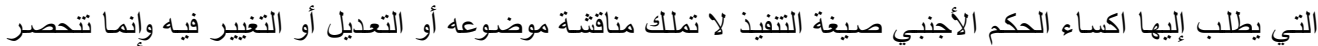
مهمة المحكمة بمراجعة توافر شروط تتفيذه وفقاً لأحكام المادة (7) من قانون تتفيذ الأحكام الأجنيبة رقم 8 لسنة 1952. وحيث أن الجهة المميزة لم تقدم ما يثبت بمخالفة الحكم المطلوب اكساءه الصيغة التنفيذية للنظام العام أو الآداب العامة

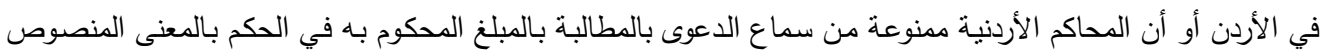




\section{Journal of Social Sciences (COES\&RJ-JSS), 5(3), pp. 425-443}

عليه في المادة (7/و) من قانون تنفيذ الأحكام الأجنبية وانه كما أسلفنا أن عبء ذلك يقع على عانق الجهة المميزة (( قرار

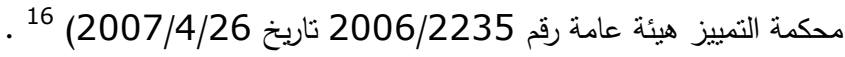

\section{ثـالـثـاً : تـرسيخ مـبـد أ الـمعــامـلـه بـالـمثل}

والذي تكون فيه الدولة التي صدر فيها الحكم تقبل تتفيذ الأحكام الأردنية بغض النظر عن وسيلة التنفيذ ـ واذا ما امعنا النظر بهذا المبدأ لوجدنا بانه يتضمن خطة تتبعها محاكم الدول إزاء بعضها البعض ، بمناسبة تتفيذ أحكام كل منها في

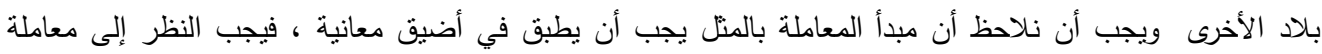

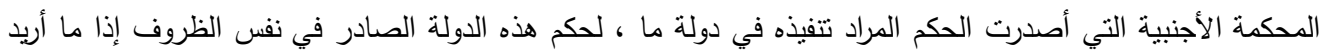

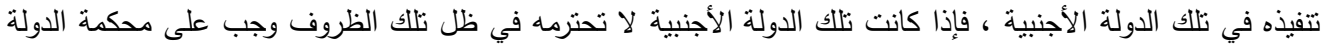

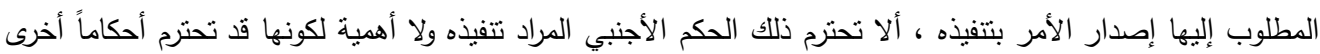

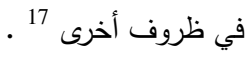

الحكم الاجنبي كل حكم يصدر من محكمة خارج المملكة يتعلق في اجراءات حقوقية ويقضي بدفع مبلغ من المال وتقام الدعوى بطلب تنفيذ حكم اجنبي باستدعاء يقدم الى المحكمة البدائية التي يقيم المحكوم عليه ضمن صلاحيتها وذلك الكات وفقا للمادتين (2 و 4) من قانون تتفيذ الاحكام الاجنبية رقم 8 لسنة 1952 كما حددت المادة لسابعة من ذات القانون

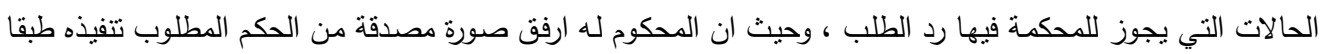
للمادة السادسة من القانون وتدل ظاهر حال الحكم انه صادر عن محكمة مختصة وانه اكتسب الدرجة القطعية ولم يرد ما لإسا يشير الى ان المحكوم عليه قد احتصل على الحكم عن طريق الاحتيال او انه مخالف للنظام العام او الاداب العامة وان التان

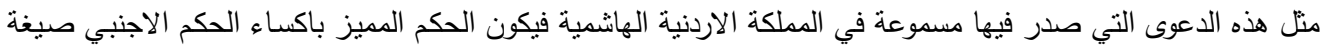

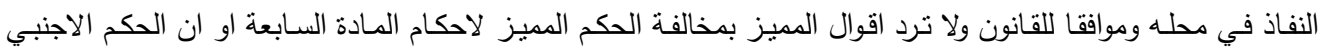
موضوع الدعوى ذو حجية نسبية وليس ذو حجية مطلقة .

اوجبت المادة السادسة من قانون تتفيذ الاحكام الاجنبية على المحكوم له تقديم صورة مصدقة عن الحكم المطلوب

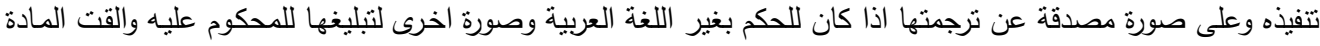

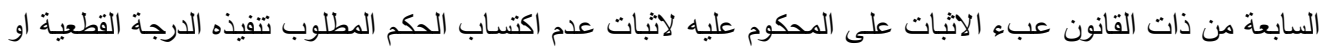

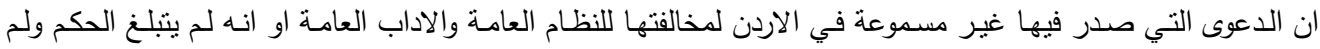

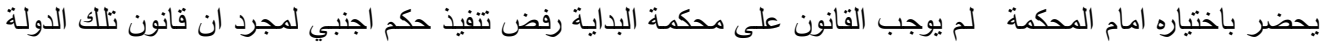

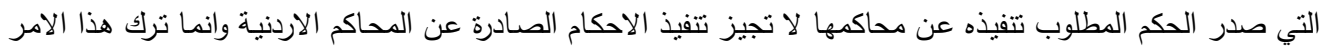

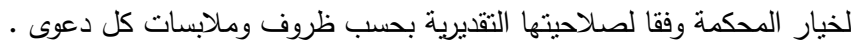
16 ـ قرار محكمة التمييز الاردنية (حقوق) رقم 2010/1921 (هيئة خماسبة) تاريخ 2011/2/21 ، منشورات مركز عدالة . 17 ـ لمزيد من التقصيل حول هذا الموضوع راجع منتدى المحامين المصرين حول مبدأ المعاملة بالمثل عبر الوصلة

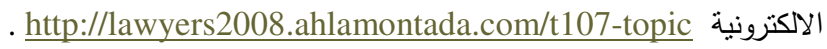




\section{Justifications of the implementation of foreign judgments in Jordan}

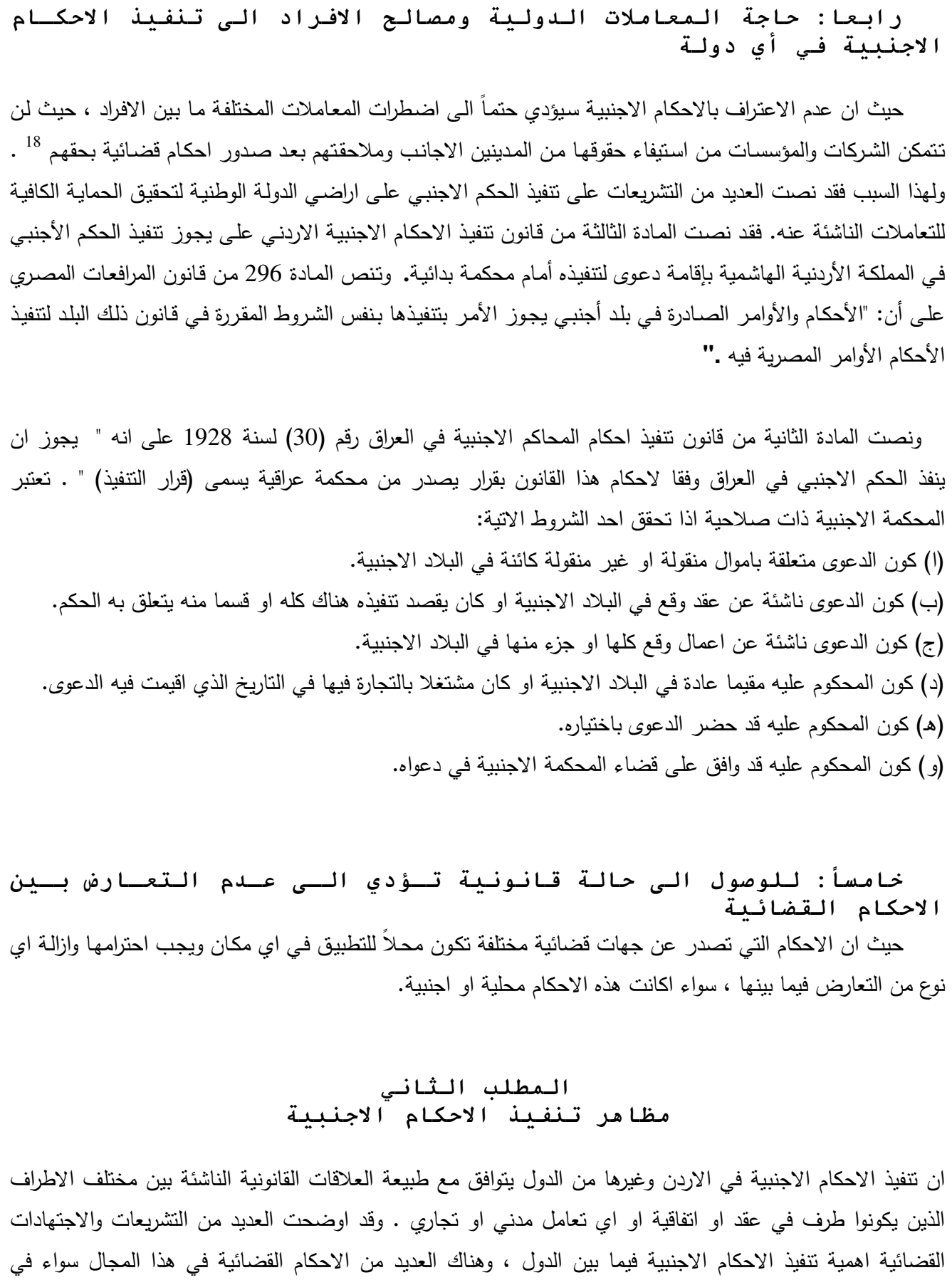


الاردن او في الدول العربية والاجنبية. وقد اوضحت المادتان 2 و5/ 2، 3 من الاتفاقية المعقدة بين جامعة الدول

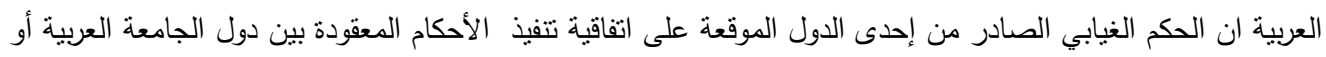

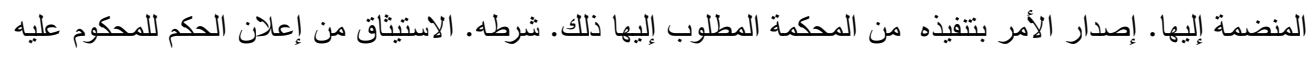

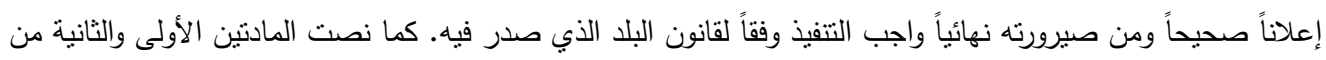

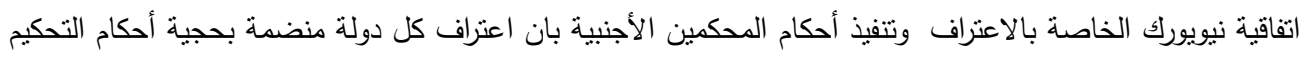

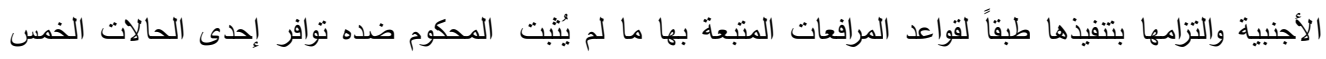
الواردة على سبيل الحصر في المادة الخامسة من الاتفاقية.

وقد قضت محكمة التمييز الاردنية بانه " تقام الدعوى بطلب تتفيذ حكم اجنبي باستذعاء يقدم الى المحكمة البدائية

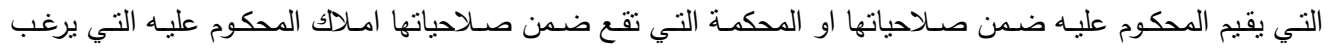

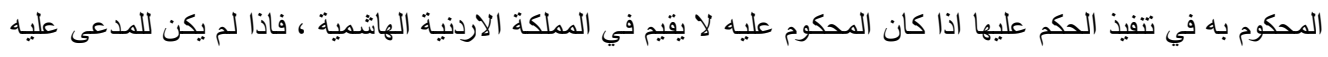

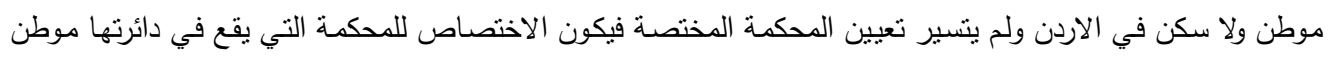

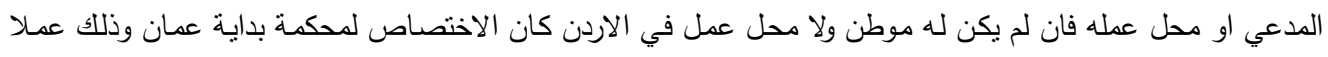

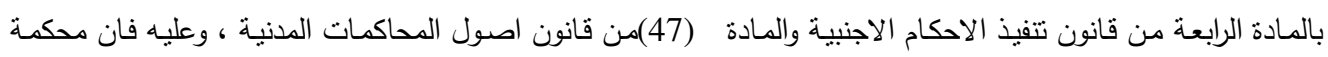

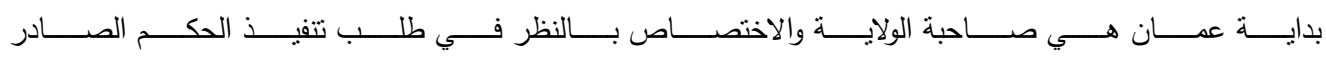

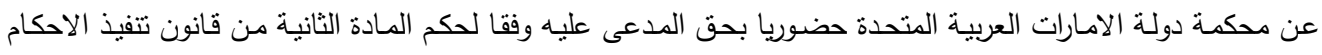

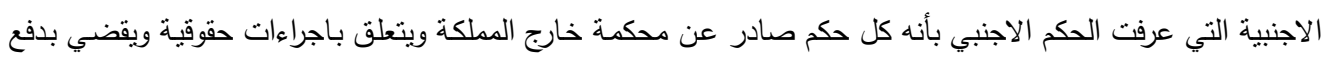
مبلغمن المال " 19.

وقضت ايضاً " استقر اجتهاد محكمة التمييز على ان المكمة التي يطلب إليها تصديق الحكم الأجنبي او اكساؤه

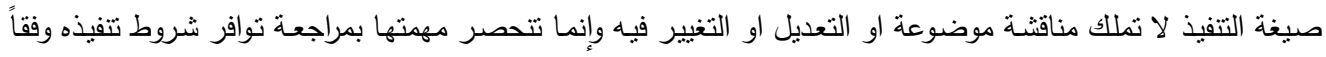

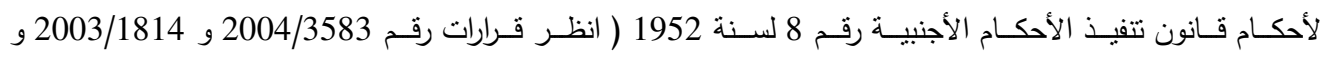

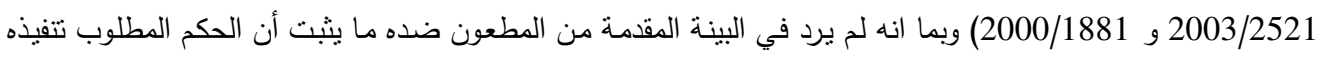

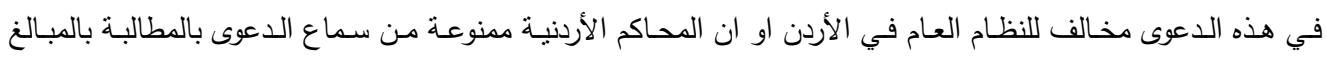

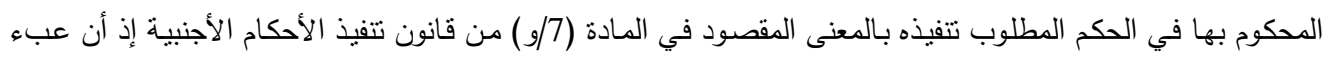
إثبات أن الحكم المطلوب تنفيذه كان بسبب دعوى لا تسمعها المحاكم الأردنية يقع على عاتق المحكوم عليه ( قرار تمييز

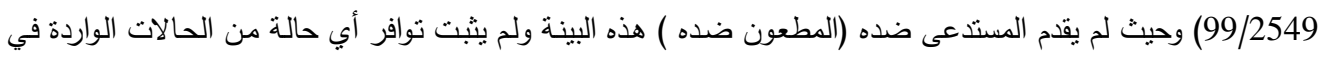

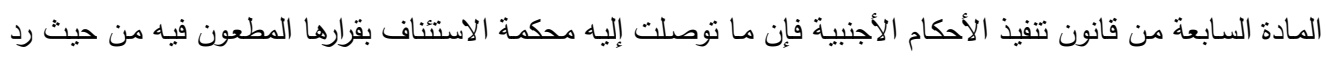

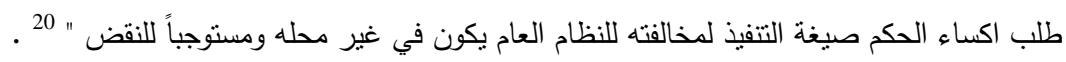

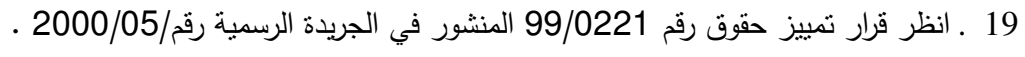

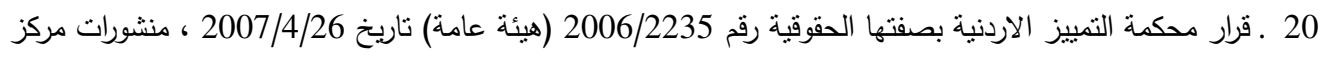




\section{Justifications of the implementation of foreign judgments in Jordan}

وفي حكم اخر " يستفاد من المادة الثانية من قانون تنفيذ الأحكام الأجنبية رقم 8 لسنة 52 انها تعرّف الحكم الأجنبي

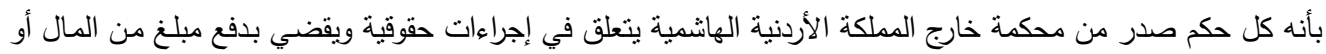

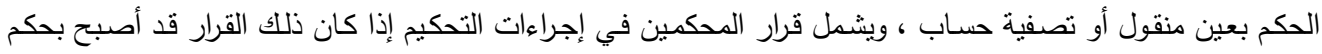

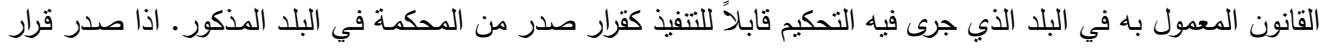

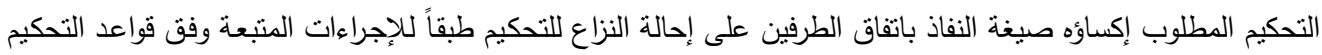

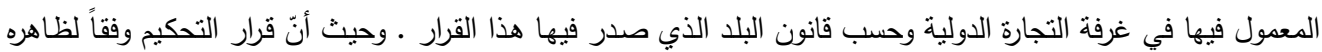

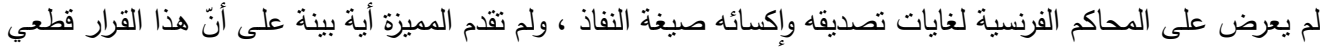

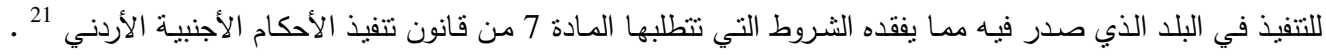

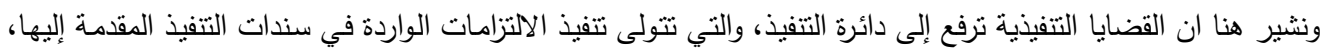
حيث تقسم سندات التتفيذ إلى نوعين : الاحكام او القرارات والسندات ، وتتشمل الاحكام أحكام المحاكم الحقوقية ، أحكام

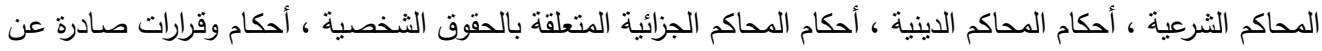

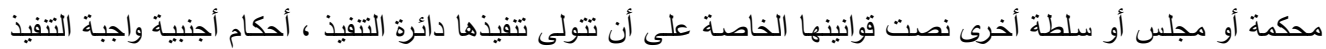

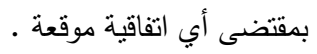

وقد نصت المادة 301 من قانون المرافعات المصري على ان المعاهدات المعقودة بين مصر وغيرها من الدول من

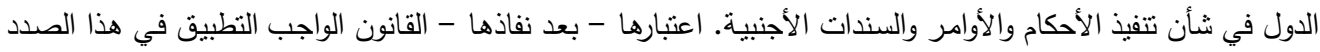

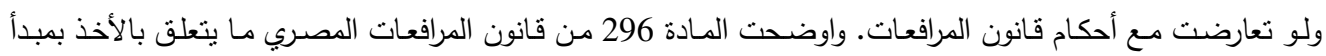

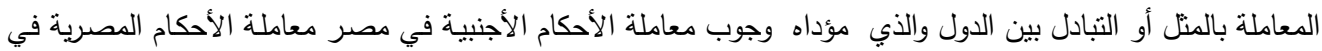
البلد الأجنبي الذي أصدر الحكم المراد تتفيذه في مصر ـ وقضت محكمة استثناف القاهرة في حكم لها بانه وبالنسبة للنظلم

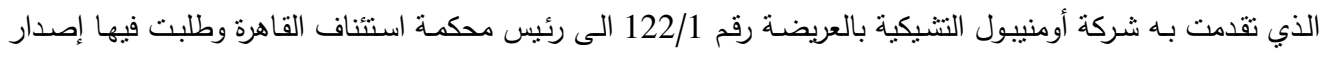

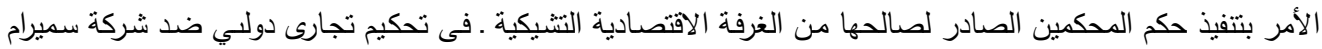

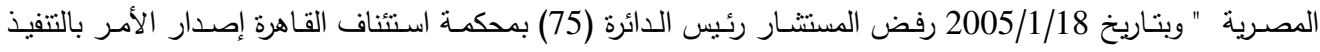

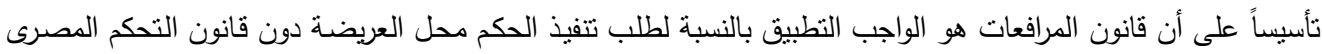

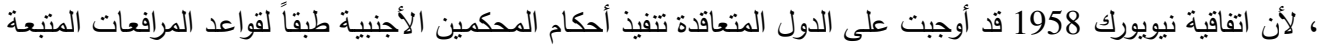

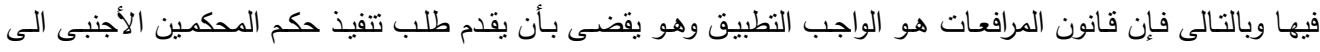

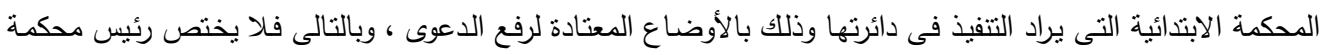
استئناف القاهرة بنظر الطلب ـ أقامت الثركة التثيكية النظلم رقم

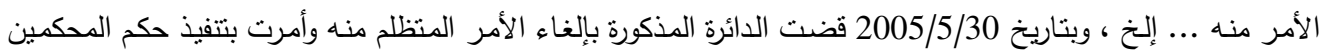

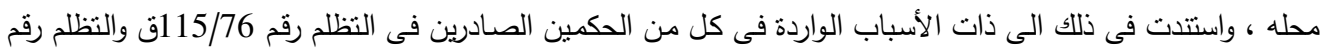

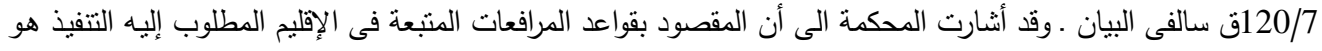

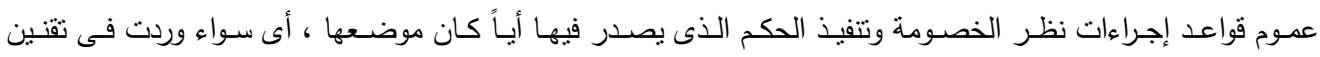

21 ـ قرار محكمة التمييز الاردنية (حقوق) رقم 2000/2803 (هيئة خماسية) تاريخ 2001/2/20 ، منشورات مركز عدالة 


\section{Journal of Social Sciences (COES\&RJ-JSS), 5(3), pp. 425-443}

المرافعات المدنية والتجاريـة أو فى أى قانون آخر ومن ذلك قانون التحكيم المصرى فهو قانون إجرائى نظم إجراءات خصومة التحكم ونظرها والحكم فيها وتتفيذه " 22 .

ونشير هنا الى ما أكدت عليه محكمة النقض المصرية حول شرط مخالفة القانون الأجنبي لمقتضيات النظام العام حيث أكدت فى حكمها الصـادر فى 19 يناير 1977" أن المقرر فى قضاء هذه المحكمـة أنه لا يجوز استبعاد أحكام

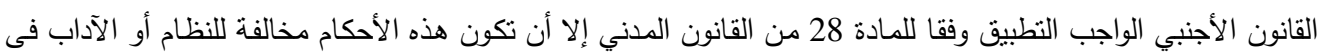

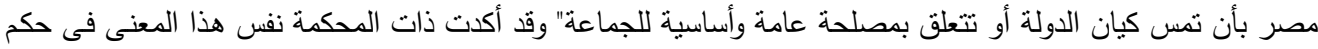

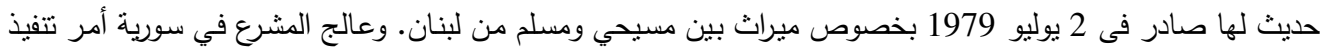

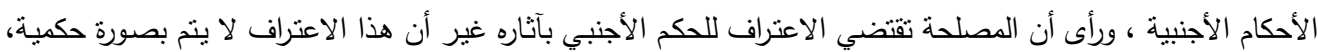

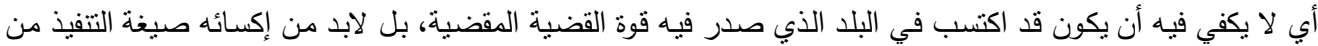

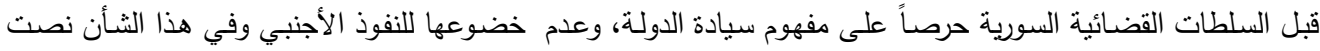
المادة 306 من قانون أصول المحاكمات الددنية على جواز تتفيذ الأحكام الأجنية في سورية بنفس الثروط المقررة في

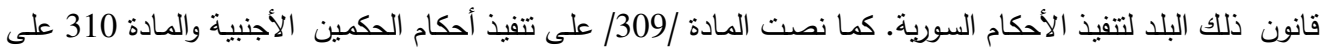

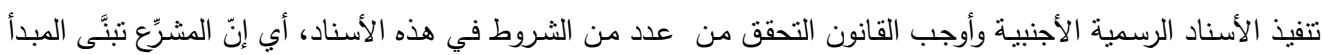

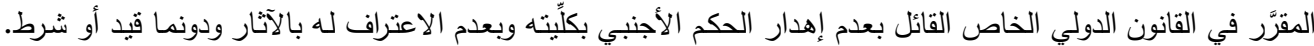
ولابد لتعريف الحكم الأجنبي من النظر إلى ملاحظتين: ناحية السلطة التي صدر باسمها الحكم وناحية الموضوع الذي بت التبات

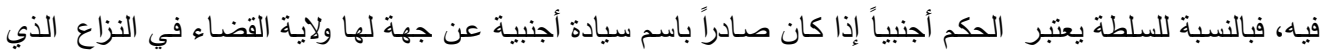
أصدرت حكمها فيه دون اعتبار للمكان الذي انعقدت فيه المحكمة مصدرة الحكم، وبالنسبة للموضوع الذي صدر فيه لاسيه

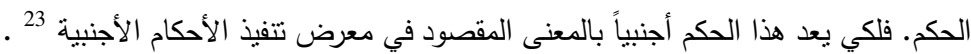

وقد اثـار المشرع التركي الى ان تنفيذ احكام المحاكم الاجنبية من مقتضيات التعاون الدولي واحترام احكام المحاكم الاجنبية ، كما انها مؤسسة قانونية لازمة لحماية حقوق الافقراد وتحقيق العدالة حيث لا يجبر اطراف النزاع على اعادة نشر

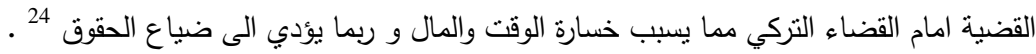

22 ـ انظر النظلم رقم 122/10 ق الصادر في محكمة استئناف القاهرة .

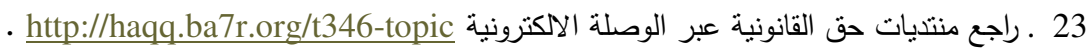

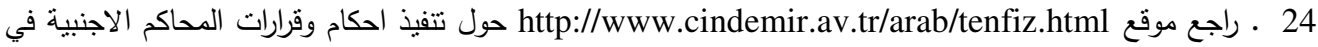

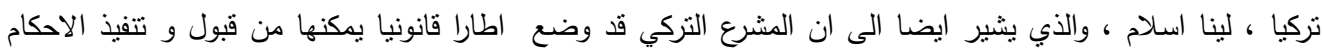

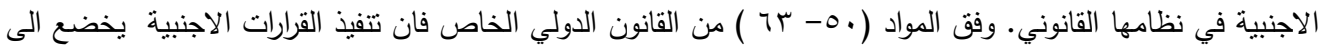
الحصول على اذن قضائي, ويكون هذا عن طريق دعوى يتم بها الاعتراف بالقرار الاجنبي و امكانية تتفيذه في تركيا. هذه الانه

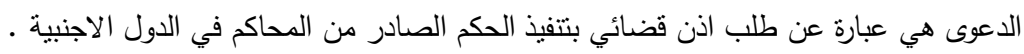




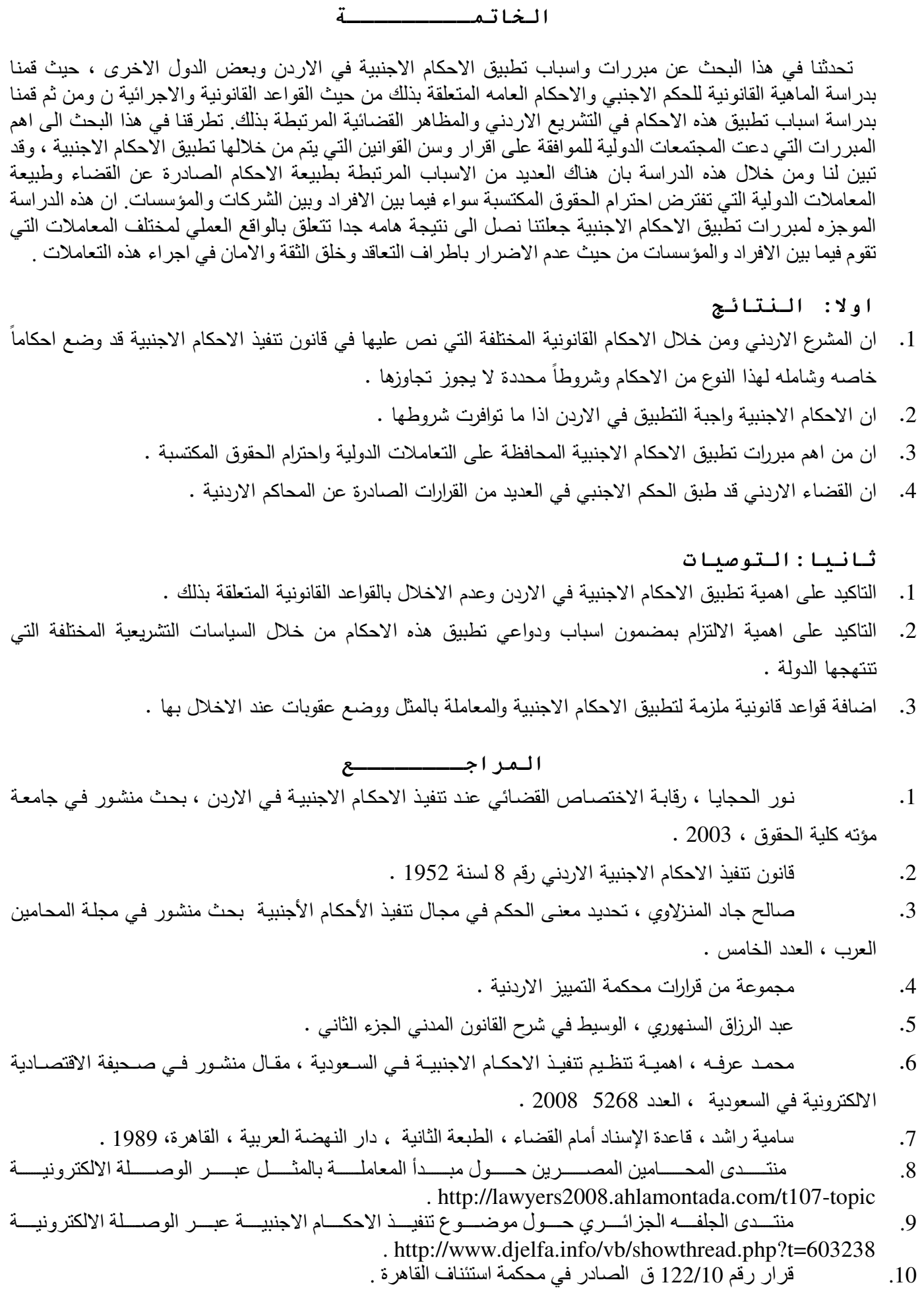


Journal of Social Sciences (COES\&RJ-JSS), 5(3), pp. 425-443

\section{English References}

1. Noor Alhjaya, Oversight Jurisdiction when Executing Foreign Judgments in Jordan, Research Published in Mutah University School of Law, 2003.

2. Implementation Act of Foreign Judgments Jordanian No. 8 of 1952.

3. Saleh Jaad Almenzlaoa, Meaning Government in the Implementation of Foreign Judgments to Identify Research, Published in the Journal of Arab Lawyers, the Fifth Issue.

4. Set of Decisions Jordanian Court of Cassation.

5. Abdul Razzaq Sanhouri, The Mediator in the Civil Law to Explain the Second Part.

6. Mohamed Arafa, The Importance of Organizing the Implementation of Foreign Judgments in Saudi Arabia, An Article Published in the Electronic Business Daily in Saudi Arabia, No. 5268, 2008.

7. Samia Rashid, Attribution Rule in Court, Second Edition, Arab Renaissance Publishing House, Cairo, 1989.

8. Lawyers Egyptians Forum on the Principle of Reciprocity through the Electronic Link http://lawyers2008.ahlamontada.com/t107-topic.

9. Algerian Djelfa Forum on the Subject of the Implementation of Foreign Judgments through the Electronic Link http://www.djelfa.info/vb/showthread.php?t=603238.

10. Resolution 10/122 Issued in Cairo Court of Appeal. 